\title{
Breves reflexões sobre a questão agrária no território amazônico
}

Brief reflections on the agrarian issue in the Amazon territory

\section{Maciana de Freitas e Souza \\ macianafreitas@hotmail.com}

Bacharela em Serviço Social pela Universidade do Estado do Rio Grande do Norte - UERN

\section{Francisco Vieira de Souza Júnior souzajunior007@yahoo.com.br \\ Bacharel em Direito pelo Centro Universitário FACEX}

\section{Aylana Paula dos Santos Silva aylana_silva@hotmail.com}

Graduanda em Letras pela Universidade do Estado do Rio Grande do Norte - UERN

\section{Resumo}

Este estudo tem como objetivo analisar a questão agrária na região amazônica e os rebatimentos socioambientais que dela decorrem. Para tanto, além de proceder à revisão da literatura, estamos ancorados nos dados produzidos pelo Atlas de Conflitos na Amazônia. O objetivo é debater acerca das implicações dessa conjuntura na efetivação dos direitos dos povos tradicionais.

Palavras-chave: Direitos Humanos; povos tradicionais; região amazônica.

\begin{abstract}
This study aims to analyze the agrarian issue in the Amazon region and the social and environmental repercussions that result from it. Therefore, in addition to reviewing the literature, we are anchored in the data produced by the Atlas of Conflicts in the Amazon. The objective is to debate about the implications of this situation in the realization of the rights of traditional peoples.
\end{abstract}

Keywords: Human rights; traditional peoples; amazon region. 


\section{Introdução}

Nas últimas décadas, podemos notar que o modelo de desenvolvimento na região amazônica tem afetado a vida de povos tradicionais e a biodiversidade existente. Importante também destacar que, mesmo com os impactos sociais e ambientais com esse modelo em curso, o Estado brasileiro tem se omitido do dever de proporcionar políticas estruturais que possam garantir os direitos territoriais e a segurança alimentar dos povos das florestas e os urbanosamazônicos.

Dentro desse contexto, este trabalho orienta-se pelo seguinte questionamento: como se apresenta a questão agrária no território amazônico e quais os impactos socioambientais nesse bioma? No que se refere à metodologia, a análise se desenvolve a partir de uma pesquisa bibliográfica através de autores que discutem a questão ambiental de forma crítica. De modo conjunto, foi realizada uma pesquisa documental com base em legislações nacionais voltadas ao desenvolvimento sustentável. Será realizada uma análise crítica dos dados com base no materialismo histórico dialético.

Para tanto, além desta breve introdução, o texto contém mais quatro seções. A primeira parte irá traçar alguns elementos a respeito da luta pelo direito à terra no Brasil. $\mathrm{O}$ segundo item focará na questão dos agrotóxicos e os impactos socioambientais do seu manejo. A terceira parte irá dialogar sobre o direito à alimentação adequada e o desmonte do Conselho Nacional de Segurança Alimentar e Nutricional (Consea) na conjuntura atual com o fortalecimento político da extrema direita. A quarta seção, por sua vez, apresentará as considerações finais, com uma síntese dos elementos centrais do texto.

Com base nesses passos, entende-se que esse estudo é importante para pensar sobre a questão agrária bem como compreender os desafios existentes para os povos originários e tradicionais devido ao aumento da crise ambiental no território amazônico. Destarte, reafirmase em sintonia com a Constituição Federal de 1988 a necessidade de um conjunto de políticas, com ênfase na prevenção ambiental da região.

\section{A luta pelo direito à terra e a questão agrária}

Desde o período colonial, é notório o caráter de desenvolvimento insustentável introduzido no Brasil, marcado pela monocultura extrativista, os latifúndios improdutivos e a extrema desigualdade da terra em sua distribuição. É importante mencionar que no período DIGNIDADE RE-VISTA | ISSN2525-698X| 2020 | V. V | N. 10 | Um olhar para a Amazônia: riquezas e diversidades. Pastoral Universitária Anchieta PUC-RIO. 
republicano surgiram diversos movimentos que tinham como base a questão agrária. Exemplos desse fato são a formação das Ligas Camponesas no Nordeste e as Revoltas de Canudos e do Contestado. Como assinala Girardi:

A questão agrária no Brasil surge com o sistema de implantação da colônia. Considerando forte peso da terra e da produção agropecuária no estabelecimento do Brasil colônia, as capitanias hereditárias e sesmarias foram a base inicial para a instauração de uma estrutura agrária e social concentrada no Brasil colônia, ditando os moldes gerais da sociedade que seria construída pela coroa portuguesa do outro lado do Atlântico. A destruição dessa estrutura agrária concentrada seria um passo importante para dar destinos mais democráticos e equitativos à sociedade brasileira. (2019, p.124)

Segundo Fernandes (2001), o processo de formação do Movimento dos Trabalhadores sem Terra inicia-se na década de 1980, quando trabalhadores rurais passaram a se reunir em diversas experiências de ocupações de terras nos Estados do Sul, São Paulo e Mato Grosso do Sul. Nesse período, ao analisar a conjuntura brasileira, pode-se identificar o contexto de luta pela democracia e de crítica ao modelo agrário implantado no período da ditadura militar. $\mathrm{Na}$ mesma perspectiva Girardi apresenta que:

Embora durante o período da Ditadura Militar (1964-1985) tenha havido a promulgação de leis a principal delas o Estatuto da Terra - que previssem algum progresso quanto a questão da terra no Brasil, nada foi feito nesse sentido. Pelo contrário, o que ocorreu de fato foi uma modernização conservadora da agricultura brasileira, com a manutenção da concentração da terra nas regiões de ocupação antiga e a abertura da fronteira agropecuária na Amazônia e nos Cerrados (Norte e Centro-Oeste), cujas terras foram apropriadas de forma ainda mais concentrada (...) e onde formou-se um importante foco - mas não exclusivo - dos conflitos e da violência no campo brasileiro, que permanece até hoje. $(2019$, p.126)

Vale ressaltar que a atuação da Comissão Pastoral da Terra no país ocorreu em função dos conflitos políticos de ocupação da Amazônia. Ela foi criada em 1975 pela Igreja Católica, com o objetivo de contribuir no processo de reforma agrária do Brasil e assessorar os trabalhadores rurais. Construída de forma participativa, a comissão tem apresentado a tarefa de denunciar os conflitos agrários com o modelo de desenvolvimento vigente. Em seu sítio eletrônico, tornou público o "Atlas de Conflitos na Amazônia”. De acordo com o documento:

Como exemplo destaca-se que em 2014 a Amazônia Legal totalizava 43,4\% dos conflitos por terra no Brasil. Trata-se, portanto, de uma região com altos índices de conflitos, consequentemente, de violência contra os camponeses. A fronteira agrícola brasileira ameaça a Amazônia de maneira escancarada desde a Ditadura Militar, e atinge hodiernamente índices ascendentes ano após ano, envolvendo o desmatamento, a violência e a barbárie no campo. Mortes e perda de biodiversidade justificadas e mascaradas em nome da expansão do capital no campo DIGNIDADE RE-VISTA | ISSN2525-698X| 2020 | V. V | N. 10 | Um olhar para a Amazônia: riquezas e diversidades. Pastoral Universitária Anchieta PUC-RIO. 
brasileiro e da ganância por concentração de terras, rotuladas como o agronegócio moderno. (ATLAS DE CONFLITOS NA AMAZỐNIA, 2018, p.16-7)

Nesse contexto, a Comissão Pastoral da Terra tem sido de fundamental importância para questionar o baixo índice de resolução das denúncias levadas ao Judiciário, e alinhada a esta perspectiva considera que o aumento da violência está relacionado ao crescimento do agronegócio no território brasileiro e ao poder coercitivo do Estado sobre os movimentos sociais. Desse modo, fica nítido que o agronegócio em curso tem promovido desigualdades e violações de direitos humanos, bem como tem apresentado rebatimentos ao meio ambiente ao colocar em risco a biodiversidade em favor do crescimento econômico.

Atividades predatórias como a pecuária extensiva de corte e exploração madeireira triplicaram em apenas uma década. O rebanho bovino, por exemplo, passou de 800 mil cabeças para três milhões e a exploração madeireira, de 300 mil metros cúbicos por ano, para mais de 1 milhão de metros cúbicos por ano em dez anos. Somente nas áreas exploradas com os planos de manejo florestal sustentável foram mais de 755 mil metros cúbicos de madeira em tora. As florestas destruí das dão lugar a pecuária. A destruição e os danos ambientais são gigantescos, com a expropriação das populações sem critério algum. Como resultado se registra também a concentração fundiária e o agravamento da pobreza. (ATLAS DE CONFLITOS NA AMAZÔNIA, 2018, p.34)

Importante ressaltar que a ocupação da Amazônia, desde fins da década de 1960, permanece pautada pela expansão do agronegócio com vista à acumulação do capital, sem considerar os danos e implicações que essa superexploração tem proporcionado ao meio ambiente. Desse modo, a produção agrícola no contexto amazônico tem sido desenvolvida sem levar em conta o interesse das comunidades tradicionais, indígenas e de famílias camponesas.

Ao mesmo tempo que a região produz mais commodities agrícolas, aumenta a desigualdade social, ou seja, aumenta a produção de soja, diminui a de alimentos tradicionais e descaracteriza a cultura alimentar local, e, consequentemente, aumenta a fome; aumentam os dispositivos de facilidades de acesso à terra aos grandes empreendimentos agrícolas, aumentam as injustiças sociais para o homem do campo e para a agricultura familiar etc. (ZUIN; AMARAL, 2018, p.432)

Dessa maneira, o processo de expansão da produção agrícola segue pela lógica da exploração dos recursos naturais, especialmente pelas atividades de madeireira, pecuária e o cultivo da soja para a produção de commodities (produção de bens primários para exportação). Nas três últimas décadas o desmatamento tem se ampliado, com isso podemos notar o crescimento de conflitos agrários, bem como danos a biodiversidade existente com o aumento das queimadas e desmatamento nessa região. 
É nesse cenário que a Amazônia vem sendo foco das atenções, porque se tornou o lugar de rentabilidade às commodities agrícolas, principalmente a da soja. Consequência da globalização sobre a terra, a expansão das fronteiras agrícolas na Amazônia resulta em desmatamento e perda da biodiversidade; essa expansão teve início nas décadas de 1960 e 1970, com incentivos governamentais para as áreas onde o solo não era considerado apropriado para cultivo. Mas o mercado econômico impulsionou os agricultores, especialmente do Sul, a se dirigirem para as regiões Centro-Oeste e Norte do País. (ZUIN; AMARAL, 2018, p.431)

No que diz respeito à Amazônia, o avanço do agronegócio vem dificultando cada vez mais as possibilidades de resistência de quem está na luta há muito tempo, propondo e construindo outras formas de viver e acessar a propriedade. A potência dos movimentos sociais e o destaque do MST como referência em produção orgânica na América Latina nos mostram que outros modelos de desenvolvimento são possíveis. É importante ressaltar que são as pequenas propriedades e a agricultura familiar que respondem por $70 \%$ dos alimentos que chegam à mesa dos brasileiros.

A expansão da fronteira agrícola sobre a Amazônia tem causado impactos sociais e ambientais ocasionados pela expansão do agronegócio e pela especulação de terras na região. Segundo Paula Andrade (2011, p.4), tais ações “desequilibram a articulação camponesa entre áreas de usufruto comum e de apropriação individual/familiar, assim como entre agricultura, pesca, extrativismo, artesanato e pequena criação". É nesse sentido que é muito importante fortalecer a luta dos povos tradicionais e dos movimentos sociais do campo articulando direitos humanos e proteção ambiental.

Nesse cenário, frente aos desmontes das políticas públicas voltadas aos povos tradicionais, é relevante que essa realidade seja discutida na mídia com uma abordagem crítica e de forma justa. Nota-se claramente que o modelo do agronegócio hoje prioriza a produção de commodities em detrimento do direito à segurança alimentar. Sob esta perspectiva, as empresas agrícolas têm utilizado métodos altamente destrutivos e aumentado o uso de agrotóxicos nas áreas de plantio, medidas que podem interferir na saúde humana.

\section{A expansão do uso de agrotóxicos na produção agrícola}

Segundo Rigotto et al. (2014), o Brasil expandiu em 190\% o mercado de agrotóxicos, ficando em primeiro lugar no ranking mundial de consumo desde 2008. Somente na safra de 2010 e 2011, foram consumidas 936 mil toneladas de agrotóxicos. Cabe, ainda, destacar que o direito humano à alimentação adequada, no artigo 25 da Declaração Universal dos Direitos 
Humanos de 1948, reconhece que é dever dos Estados signatários garantir por meio de políticas públicas o acesso permanente e regular, de forma socialmente justa, pautada em um modelo de produção sustentável.

O artigo 225 da Constituição brasileira diz que "todos têm direito ao meio ambiente ecologicamente equilibrado, bem de uso comum do povo e essencial à sadia qualidade de vida". E assegura que "é dever do Poder Público e da coletividade defendê-lo e preservá-lo para as presentes e futuras gerações”. Desse modo, é notório que o Estado brasileiro tem atuado no sentido contrário dos tratados internacionais como também da nossa Constituição Cidadã, com alianças voltadas à burguesia agrária e ao agronegócio.

Por sua vez, o uso de tais produtos químicos vem ocasionando a redução da qualidade de vida e produtividade nas populações afetadas. Esses dados evidenciam que o modelo de desenvolvimento agrário tem contribuído apenas para a expansão do agronegócio e do grande capital, e podemos notar, ainda, o aumento de pessoas afetadas pelo uso indiscriminado de agrotóxicos, seja pelos cuidados reduzidos durante o manejo, seja pela flexibilidade no seu controle pelas agências estatais.

Na busca da agropecuária de alta produtividade e preços competitivos no mercado internacional, tem colocado o Brasil na liderança do ranking de consumo mundial de agrotóxicos. (...) o uso intenso destes químicos tem elevado o risco à saúde humana, animal e ao meio ambiente, principalmente, pelo mau uso em decorrência de sua aplicação inadequada ou descontrolada, assim como, o desrespeito com o intervalo de segurança entre a aplicação e a colheita dos alimentos. (PEREIRA et al., 2018, p.40)

Segundo o estudo "Agrotóxicos no Brasil, padrões de uso, política da regulação e prevenção da captura regulatória", produzido pelo Instituto de Pesquisa Econômica Aplicada (IPEA), com relação ao quadro geral indica que "o Brasil consumia em 1991 cerca de sete vezes menos agrotóxicos que os Estados Unidos, enquanto em 2015 as quantidades no Brasil e nos Estados Unidos foram próximas, cada um respondendo por cerca de $10 \%$ do consumo mundial" (MORAES, 2019, p.19).

Percebe-se ainda, de acordo com a pesquisa citada, que os trabalhadores da indústria e os rurais são os primeiros afetados pelo uso direto, e podemos observar também o avanço da contaminação do solo e da água, com riscos à biodiversidade. Como assinalado, o modelo agroexportador traz consigo impactos à saúde humana pelo uso dos agrotóxicos na produção agrícola além de danos ao meio ambiente. Como menciona Bruno, “O agronegócio despontou como palavra política unificadora de interesses das classes e grupos dominantes no campo e 
expressão do processo de construção da hegemonia e de renovação dos espaços de poder e de dominação" (BRUNO, 2009, p.114).

Tais resultados apresentam uma deficiência nas políticas de controle de agrotóxicos nas últimas décadas. Não sem razão, este contexto tem grande impacto sobre a saúde humana. O cenário ilustra ainda um aumento significativo do número de pessoas afetadas com a exposição, e sugere, ao mesmo tempo, a possibilidade de crescimento, tendo-se em conta as mudanças no processo de avaliação e registro de agrotóxicos.

No momento atual, temos um grande desafio quanto ao monitoramento da exposição aos agrotóxicos, pelo desmonte provocado pelo governo federal nos órgãos de fiscalização, fazendo-se necessária uma luta constante pela efetivação dos direitos humanos. Ademais, com o acirramento da crise ambiental, a trajetória no campo da agroecologia deve ser pautada no processo de elaboração de políticas públicas voltadas a uma alimentação segura.

\section{Desafios para a efetivação do direito à alimentação adequada}

O Direito Humano à Alimentação Adequada está presente no artigo 25 da Declaração Universal dos Direitos Humanos de 1948, cujo documento o Brasil é signatário. Uma vez que a alimentação constitui uma necessidade básica do ser humano, cabe ao Estado a responsabilidade de criar serviços e políticas públicas para o seu acesso. Quanto ao ordenamento jurídico brasileiro, temos a inclusão da alimentação como uma das garantias fundamentais da Constituição Federal de 1988, como assegura o Art. $6^{\circ}$ :

São direitos sociais a educação, a saúde, a alimentação, o trabalho, a moradia, o transporte, o lazer, a segurança, a previdência social, a proteção à maternidade e à infância, a assistência aos desamparados, na forma desta Constituição. (BRASIL, 1988)

Outro passo nesse sentido foi a criação da Lei Orgânica de Segurança Alimentar e Nutricional (Losan - Lei $n^{\circ}$ 11.346/2006) e do Sistema Nacional de Segurança Alimentar e Nutricional (Sisan), com vistas a assegurar o direito humano à alimentação adequada. Quando tratamos desse processo, podemos mencionar que o conceito de segurança alimentar tem como objetivo não somente a garantia do direito alimentar como também reconhece a importância de uma alimentação que leve em conta a sustentabilidade. Conforme o art. 3 da Losan: 
A segurança alimentar e nutricional consiste na realização do direito de todos ao acesso regular e permanente a alimentos de qualidade, em quantidade suficiente, sem comprometer o acesso a outras necessidades essenciais, tendo como base práticas alimentares promotoras de saúde que respeitem a diversidade cultural e que sejam ambiental, cultural, econômica e socialmente sustentáveis (BRASIL, 2006).

Mais recentemente, com a medida provisória $\mathrm{n}^{\circ} 870$, de $1^{\circ}$ de janeiro de 2019 , é revogado o Conselho Nacional de Segurança Alimentar e Nutricional (Consea), órgão criado para debater e apresentar diretrizes para garantir a segurança alimentar no país. Importante ressaltar que, a extinção do Consea acentua os desafios na garantia do Direito Humano à Alimentação Adequada (DHAA), pois esta era uma instância responsável pela articulação de diversas políticas e programas para promover o direito à alimentação de forma mais justa e democrática.

No Brasil, a agroecologia emerge a partir do final dos anos 1970, por iniciativas de organizações não governamentais de assessoria, movimentos sociais, Comunidades Eclesiais de Base (CEBS) e organizações de trabalhadores/as do campo. A introdução do modelo agroecológico e o fomento de políticas públicas para a agricultura familiar com o Decreto $\mathrm{n}^{\circ}$ $7.794 / 2012^{1}$ constituiu um importante passo no acesso ao direito à alimentação adequada. Contudo, a extinção do Consea tem impacto sobre a implantação das políticas públicas nacionais.

A participação social e a discussão entre os diversos setores da sociedade são fundamentais para uma agenda pública voltada para a garantia de direitos. Por sua vez, a “(...) a extinção do Consea representa uma afronta à democracia e um retrocesso social, uma vez que desmonta um espaço de participação, um dos pilares da democratização do Estado, conforme pactuado na Constituição Federal" (CASTRO, 2019, p.2). Por isso, entende-se que tais ações podem dificultar o avanço da Segurança Alimentar e Nutricional e maiores investimentos em projetos destinados a agricultura familiar.

A despeito das medidas em curso pelo Estado brasileiro, como afirma o sociólogo Florestan Fernandes $(2008$, p.58) as “(...) fases novas não eliminam as anteriores; ao contrário, coexistem e engendram um sistema econômico capitalista segmentado, no qual as diferentes estruturas compõem um todo". Dessa forma, as políticas estatais se constituem mais

\footnotetext{
1 A Política Nacional de Agroecologia e Produção Orgânica (PNAPO), instituída pelo Decreto n. 7.794/2012, integra um grande conjunto de ações, programas e políticas, articulando diretamente 14 órgãos governamentais. Sua gestão é feita de forma paritária envolvendo governo e representantes da sociedade civil. A operacionalização da PNAPO tem por base os Planos Nacionais de Agroecologia e Produção Orgânica.
}

DIGNIDADE RE-VISTA | ISSN2525-698X| 2020 | V. V | N. 10 | Um olhar para a Amazônia: riquezas e diversidades. Pastoral Universitária Anchieta PUC-RIO. 
convenientes às classes dominantes, tornando visíveis as desigualdades no acesso aos direitos, elementos que fazem parte de uma dinâmica societária que tem primazia pelo lucro.

\section{Considerações finais}

Este trabalho buscou compreender de forma geral o avanço da questão agrária no território amazônico e os impactos socioambientais para as comunidades e o meio ambiente. É importante olharmos com sensibilidade para os campesinos e os povos das florestas, devemos estar preparados para apontar que os ganhos de meia dúzia de capitalistas brasileiros não representam "um ganho para o Brasil".

Como se pode perceber, a sobrevivência das populações tradicionais depende da preservação da Amazônia. Contudo, as ações vigentes pelo governo brasileiro estão voltadas para o crescimento econômico, o que acaba por promover o desmonte ao direito à terra/ território das populações locais e riscos ambientais para a presente e as futuras gerações. Portanto, no contexto atual, é fundamental intensificar as fiscalizações nas áreas protegidas, para impedir mais retrocessos do ponto de vista socioambiental.

Como visto, o modelo de produção vigente amplia o desmatamento, a exploração predatória e a grilagem de terras no território amazônico. Assim sendo, é necessário refletir sobre essas práticas e lutar em defesa dos direitos humanos e da biodiversidade existente. Além disso, o Direito humano à alimentação possui duas dimensões: o direito de estar livre da fome e da má nutrição e o direito à uma alimentação adequada - e para a realização dessas duas dimensões do DHAA todos os demais direitos humanos precisam ser garantidos. Em vista disso, fica clara a importância do reconhecimento da população que a alimentação se constitui um direito fundamental e se faz necessária a ampliação de recursos destinados às políticas públicas sustentáveis. 


\section{Referências bibliográficas}

ANDRADE, Maristela. O cerco das terras camponesas e a destruição dos recursos naturais pela Suzano Papel e Celulose. In: $35^{\circ}$ Encontro Anual da ANPOCS, Caxambu (MG), 2011. p.1-19. Disponível em: https://anpocs.com/index.php/papers-35-encontro/gt-29/gt03-15/862-asuzana-o-cerco-das-terras-camponesas-e-a-destruicao-dos-recursos-naturais-pela-suzanopapel-e-celulose-no-maranhao/file Acesso em: 4 dez 2019.

BRASIL. Lei 11.346, de 15 de setembro de 2006. Disponível em: http://www.planalto.gov.br/ccivil_03/_Ato2004-2006/2006/Lei/L11346.htm Acesso em: 4 dez de 2019

1988.

Constituição da República Federativa do Brasil. Brasília, DF: Senado Federal,

. Decreto $n^{o}$ 7.794, de 20 de agosto de 2012. Institui a Política Nacional de

Agroecologia e Produção Orgânica. Disponível em: http://www.planalto.gov.br/ccivil_03/_Ato2011-2014/2012/Decreto/D7794.htm Acesso em: 4 $\operatorname{dez} 2019$.

Medida provisória $n^{o}$ 870, de 2019. Disponível em: https://legis.senado.leg.br/sdleg-getter/documento?dm=7914413\&disposition=inline Acesso em: 4 dez 2019.

BRUNO, Regina. Um Brasil ambivalente: agronegócio, ruralismo e relações de poder. Rio de Janeiro: Mauad, 2009.

CASTRO, Inês. A extinção do Conselho Nacional de Segurança Alimentar e Nutricional e a agenda de alimentação e nutrição. Caderno de Saúde Pública, v.35, n.2, 2019. Disponível em: http://cadernos.ensp.fiocruz.br/csp/public_site/arquivo/CSP_0099_19_editorial_v35n2_pt.pdf Acesso em: 4 nov 2019.

COMISSÃO PASTORAL DA TERRA. Atlas de Conflito na Amazônia. Goiânia: CPT; São Paulo: Entremares, 2017. Disponível em: https://cptnacional.org.br/downloads-2/send/25cartilhas/14066-atlas-de-conflitos-na-amazonia Acesso em: 4 dez 2019.

FERNANDES, Bernardo. A formação do MST no Brasil. São Paulo: Cortez, 2001.

FERNANDES, Florestan. Sociedade de classes e subdesenvolvimento. São Paulo: Global, 2008.

GIRARDI, Paulon. Questão agrária, conflitos e violências no campo brasileiro. Revista NERA, v.22, n.50, p.116-34, 2019. Disponível em: http://revista.fct.unesp.br/index.php/nera/article/viewFile/6611/5065 Acesso em: 4 dez 2019.

MORAES, Rodrigo. Agrotóxicos no Brasil: padrões de uso, política da regulação e prevenção da captura regulatória. Brasília: Instituto de Pesquisa Econômica Aplicada (Ipea), setembro de 2019. 
PEREIRA, Patrícia et al. Uso de agrotóxicos em áreas antropizadas da Amazônia Ocidental pela agricultura familiar. Revista Ibero-Americana de Ciências Ambientais, v.9, n.8, p.39-45, 2018. Disponível em: http://sustenere.co/index.php/rica/article/view/CBPC21796858.2018.008.0004/1424 Acesso em: 4 dez 2019.

RIGOTTO, Raquel; VASCONCELOS, Dayse; ROCHA, Mayara. Uso de agrotóxicos no Brasil e problemas para a saúde pública. Caderno de Saúde Pública, v.30, n.7, 2014. Disponível em: http://www.scielo.br/pdf/csp/v30n7/pt_0102-311X-csp-30-7-1360.pdf Acesso em: 4 dez 2019.

ZUIN, Aparecida; AMARAL, Jorge. Direito alimentar e risco na sociedade moderna: a Amazônia e o agronegócio. Revista Direito Práxis, Rio de Janeiro, v.9, n.1, p.417-42, 2018. Disponível em: http://www.scielo.br/pdf/rdp/v9n1/2179-8966-rdp-9-1-417.pdf Acesso em: 4 $\operatorname{dez} 2019$. 